\title{
Psychological adaptation and its impact on the quality of life and spiritual well-being: A cross-sectional study of end of life cancer patients
}

\author{
Filomena Moreira Pinto Pereira ${ }^{1 *}$ and Célia Samarina Vilaça de Brito Santos ${ }^{2}$ \\ ${ }^{1}$ Nursing Sciences at Universidade Católica Portuguesa, Escola Superior de Enfermagem do Porto (Nursing School of Porto), Portugal \\ ${ }^{2}$ Psychology at Universidade do Porto, Escola Superior de Enfermagem do Porto (Nursing School of Porto), Portugal
}

\begin{abstract}
Background: The person's perception of self-vulnerability and finitude has an emotional impact on patient, causing stress and will trigger a process leading to the adoption of coping skills aiming to a better psychological adaptation, that affects quality of life and on spiritual well-being.

Aim: To determine the coping strategies of end-of-life patients under palliative care and their impact on spiritual well-being and quality of life.

Design: An exploratory, descriptive and cross-sectional study was developed using the socio-demographic and clinical questionnaire, the Mini-MAC Scale, FACT-G and the FACIT-Sp.

Setting/participants: The study was administered to 346 end-of-life cancer patients undergoing palliative care, with symptoms under control, in an oncology hospital in Portugal.

Results: The coping skills used by patients were mainly emotion-focused like "Cognitive Avoidance" and "Fatalism". Coping was influenced by both sociodemographic and disease variables. There was correlation between quality of life and spiritual well-being. Coping strategies like "Fighting Spirit" and "Fatalism" proved to be the most adaptive and predictive of better quality of life and spiritual well-being.

Conclusions: Coping should be a focus for health professionals caring for end-of-life cancer patients and because they experience intense suffering, they need help in developing more adaptive coping skills in this phase.
\end{abstract}

\section{Introduction}

The end-of-life stage is characterized as being the last phase for numerous chronic diseases, including cancer, with no response to available or specific treatments, with a life expectancy less than six months [1]. In this stage of serious illness, the patient's responses will be determined by perception on the disease and personal, social and family available resources $[2,3]$. This is also influenced by the ability and dedication of the health team, focusing on active caring and the relief of suffering while patient is under palliative care [4]. This perception will set the beginning of a coping process, consisting on the adoption of new coping responses to deal or adapt to the new situation $[5,6]$.

Coping is conceptualized in the Transactional Model of Stress and Coping [7], as a set of cognitive and behavioural efforts that aim to manage specific internal and external demands that arise in situations of stress and which are perceived as a burden or beyond the person's capabilities [5].

The adopted coping skills may influence not only patients' quality of life, but may also prolong their lives [8,9]. Based on in the Transactional Model of Stress and Coping [7], Greer and Watson [9], while studying the patients' mental adjustment to cancer, identified the following five types of coping responses, including on Mini-Mac Scale [10]: "Fighting Spirit", "Cognitive Avoidance", "Fatalism", "Helplessness/Hopelessness", "Anxious Preoccupation”.
The Mental Adjustment to Cancer (MAC) scale was developed in order to evaluate the responses developed by patients during their psychological adaptation to diagnosis and treatment of cancer. The Mini-MAC Scale has been used as a measure of coping strategies or coping styles $[9,10,11]$.

This study aimed at improving knowledge regarding the coping strategies, adopted by these patients. It is important to foster an improved health professionals' support to ensure a better spiritual wellbeing and quality of life for end-of-life oncological patients.

\section{Methods}

An exploratory, descriptive and cross-sectional study was developed, aiming at: identify the coping strategies most commonly adopted by end-of-life oncological patients; analyse the influence of sociodemographic and clinical variables in the adopted coping skills;

Correspondence to: Filomena Moreira Pinto Pereira, Escola Superior de Enfermagem do Porto Rua Dr. António Bernardino de Almeida, 4200-072 Porto, Portugal; Tel: 003512250735 00; E-mail: fpinto@esenf.pt

Key words: cancer, coping skills, end of life, palliative care, psychological adaptation, quality of life

Received: July 22, 2016; Accepted: August 05, 2016; Published: August 09, 2016 
analyse the predictability index of coping skills on spiritual well-being and quality of life of end-of-life oncological patients.

\section{Participants}

An intentional sample of 346 end-of-life cancer patients was recruited from palliative care services in an oncology hospital in Portugal. Participants had to meet the following eligibility criteria: (a) be aged 16 years or over; (b) diagnosed with incurable cancer in an advanced and progressive state, without acceptable antineoplastic therapeutic response and under palliative care (inpatient and outpatient); (c) not to exhibit symptoms with an intensity more than 5 , evaluated through the Edmonton Symptom Assessment Scale (ESAS); (d) not to present cognitive alterations, evaluated by the Portuguese version of the Mini-Mental State (MMS) [12] .

The sample, presented in table 1, included patients with different oncological diseases, of which $51.7 \%$ were males and $48.3 \%$ females, aged between 22 and 91 years $(M=65.1 ; S D=13.3)$. They had between 0 and 23 years schooling $(\mathrm{M}=4.8, \mathrm{SD}=3.9)$, working in a wide range of professional fields, or were retired or unemployed (84.1\%). On average, they had 2.6 children $(\mathrm{SD}=2.2)$ and lived in the same house with two other people $(\mathrm{SD}=1.4)$.

On average, the cancer lasted 35 months $(S D=27.6$, Min $=1$ month, Max 180 months).

\section{Material}

The following instruments were used in the study:

1. Socio-demographic and clinical questionnaire;

2. Mini Mental Adjustment to Cancer Scale (Mini-MAC Scale)

Table 1. Socio-demographic and clinical characteristics of the sample.

\begin{tabular}{|l|c|}
\hline Gender & n (\%) \\
\hline Male & $179(51.7)$ \\
\hline Female & $167(48.3)$ \\
\hline Marital Status & $233(67.3)$ \\
\hline Married & $56(16.2)$ \\
\hline Widow/Widower & $34(9.8)$ \\
\hline Single & $23(6.6)$ \\
\hline Other (divorced, separated, civil union) & \\
\hline Age Group & $55(15.9)$ \\
\hline $20-50$ & $63(18.2)$ \\
\hline $51-60$ & $84(24.3)$ \\
\hline $61-70$ & $111(32.1)$ \\
\hline $71-80$ & $33(9.5)$ \\
\hline $81-100$ & $45(13.0)$ \\
\hline Employment Status & $287(82.9)$ \\
\hline Active, on sick leave & $14(4.1)$ \\
\hline Inactive (Retired) & \\
\hline Others (active - self-employed; housewife; inactive - unemployed) & $324(93.6)$ \\
\hline Religion/Religious Belief & $9(2.7)$ \\
\hline Catholic & $13(3.8)$ \\
\hline Others (Evangelical; Christian Congregation; Jehovah's Witness) & $60(26.0)$ \\
\hline None & $61(17.6)$ \\
\hline Treatments Given & $46(13.3)$ \\
\hline Surgery + chemotherapy + radiotherapy & $75(21.7)$ \\
\hline Surgery + chemotherapy & $14(4.0)$ \\
\hline Surgery & \\
\hline Chemotherapy & \\
\hline Others (hormone therapy, brachytherapy, etc) & \\
\hline None & \\
\hline & \\
\hline
\end{tabular}

of Watson et al. [10]. The Portuguese version was used translated and adapted by Pais-Ribeiro et al. [11], retaining the structure of MiniMental Adjustment to Cancer (Mini-MAC) Scale. The scale consists of 29 items on a four-point numeric scale and grouped into five dimensions: "Helplessness/Hopelessness", "Anxious Preoccupation", "Fighting Spirit", "Cognitive Avoidance", and "Fatalism", and it is not possible to obtain an overall result. On this scale, the higher the response grading, the higher is the adoption of the coping responses under analysis. This version was later adapted and validated for the population under study [13].

3. Functional Assessment of Cancer Therapy-General Scale (FACT-G) version 4 developed by Cella et al. [14]. It is a functional scale of the overall quality of life, consisting of 27 items assessing four quality of life domains: Physical Well-Being; Functional Well-Being; Social/Family Well-Being, and Emotional Well-Being. Answers are presented using a five-point Likert-type scale. Scores from each four sub-scales can be added to obtain a global quality of life score. Hence higher ratings mean better quality of life in the various dimensions [14]. This scale was adapted and validated for the population under study [15].

Functional Assessment of Chronic Illness Therapy-Spiritual WellBeing Scale (FACIT-Sp) of Peterman et al. [16] that assess the spiritual well-being. This scale focuses on existential aspects of spirituality and faith. It consists of 12 items, comprising two subscales/dimensions, meaning/peace and faith. The responses to the items are presented using a Likert agreement five-point scale, and higher values mean better quality of life/better spiritual well-being [16]. This scale was adapted and validated for the population under study [17].

\section{Ethics}

Ethical approval was obtained from the institution where data were collected. The informed consent was obtained from the participants after being informed of the study's purposes. Participants' confidentiality was ensured and they were informed that they could withdraw their consent at any time during the study.

The instruments used were equally given approval by the respective authors.

\section{Results}

To identify the most adopted coping responses by patients, the Mini-MAC was used, as shown in results displayed in Table 2. Higher mean scores are evidenced in responses such as "Cognitive Avoidance" and "Fatalism". Coping responses revealing lower values are "Fighting Spirit", "Anxious Preoccupation" and "Helplessness/Hopelessness".

It was also found that the coping strategies used were influenced by gender, age, education and religion. Thus, according to Table 3 , women registered higher mean scores $(n=167$, Mean $=21.02, S D=8.10)$ related to the adoption of the coping responses "Helplessness/Hopelessness" showing a highly significant difference between the men and women groups ( $\mathrm{t}(344=-3,35, \mathrm{p}=0,001)$. Also "Fighting Spirit" ( $\mathrm{t}(344=-2,5$, $\mathrm{p}=0,01)$ evidenced significant difference between the men and women groups, with men registering a higher mean score ( $\mathrm{n}=179$, Mean=10,71, $\mathrm{DP}=4,29$ ). These data reveal that, at the end-of-life stage, women tend to adopt coping responses related to "Helplessness/Hopelessness" whilst men are more likely to adopt responses related to "Fighting Spirit".

Regarding the age variable, results show negative, poor, but significant correlation between age and the adoption of coping 
Table 2. Distribution of minimum (Mn), maximum (Mx), mean and standard deviation (SD) and mean scores of Mini-MAC subscales.

\begin{tabular}{|c|c|c|c|c|c|c|}
\hline $\begin{array}{l}\text { Sub-Scales/ } \\
\text { Dimensions }\end{array}$ & No. of items & Mn & Mx & Mean & SD & $\begin{array}{l}\text { Mean } \\
\text { Score }\end{array}$ \\
\hline Helplessness/Hopelessness & 8 & 8 & 32 & 19,45 & 8,51 & 2,43 \\
\hline Anxious Preoccupation & 8 & 8 & 32 & 20,03 & 7,72 & 2,50 \\
\hline Fighting Spirit & 4 & 4 & 16 & 10,16 & 4,28 & 2,54 \\
\hline Cognitive Avoidance & 4 & 4 & 16 & 13,14 & 3,94 & 3,29 \\
\hline Fatalism & 5 & 5 & 20 & 15,53 & 4,14 & 3,11 \\
\hline
\end{tabular}

Table 3. Distribution of mean, standard deviations and $t$ test and Mini-MAC subscale/dimensions according to gender.

\begin{tabular}{|c|c|c|c|c|c|c|c|c|}
\hline \multirow[t]{3}{*}{ Sub-Scales } & \multicolumn{6}{|c|}{ Groups } & \multirow[t]{3}{*}{$t$} & \multirow[t]{3}{*}{$\mathbf{p}$} \\
\hline & \multicolumn{3}{|c|}{ Male $n=179$} & \multicolumn{3}{|c|}{ Female $n=167$} & & \\
\hline & Mean & Mean Score & SD & Mean & Mean Score & SD & & \\
\hline $\begin{array}{l}\text { Helplessness-Hopelessness } \\
8 \text { items }\end{array}$ & 17,99 & 2,25 & 8,64 & 21,02 & 2,63 & 8,11 & 3,35 & 0,001 \\
\hline $\begin{array}{l}\text { Anxious Preoccupation } \\
8 \text { items }\end{array}$ & 19,92 & 2,49 & 7,68 & 20,16 & 2,52 & 7,77 & $-0,29$ & Ns \\
\hline $\begin{array}{l}\text { Fighting } \\
\text { Spirit } \\
4 \text { items }\end{array}$ & 10,71 & 2,68 & 4,29 & 9,57 & 2,39 & 4,20 & $-2,49$ & 0,01 \\
\hline $\begin{array}{l}\text { Cognitive Avoidance } \\
4 \text { items }\end{array}$ & 12,98 & 3,25 & 3,94 & 13,32 & 3,33 & 3,94 & $-0,78$ & Ns \\
\hline $\begin{array}{l}\text { Fatalism } \\
5 \text { items }\end{array}$ & 15,59 & 3,12 & 4,38 & 15,47 & 3,09 & 3,88 & 0,28 & Ns \\
\hline
\end{tabular}

responses related to "Anxious Preoccupation" ( $\mathrm{r}=-0.27, \mathrm{p} \leq 0,01)$ and "Fighting Spirit" $(\mathrm{r}=-0.17, \mathrm{p} \leq 0,01)$. The educational level of the participants, only showed positive, poor and low significant correlation in the coping responses related to "Fighting Spirit" $(r=0.10, p=0.04)$, which may predict that patients with higher educational level will adopt this strategy.

When addressing religion, the Mann-Witney $U$ Test, showed differences between the two groups believers $(n=333)$ and nonbelievers $(\mathrm{n}=13)$ with a highly significant difference in the adoption of "Fatalism" $(\mathrm{U}=821 ; \mathrm{p}=0,0001)$ and low significant differences in "Cognitive Avoidance" ( $U=1460,5 ; p=0,03)$ The group of "believers" evidenced the highest two subscales mean rank, with 177,53 on Fatalism subscale and 175,61 on Cognitive Avoidance subscale.

In addition to the influence of sociodemographic variables in the adoption of coping skills, the effect of some clinical variables was also evidenced, such as: diagnosis time (time elapsed from diagnosis); type of treatment; type of assistance (outpatient or inpatient). In what concerns time elapsed from the disease diagnosis there was only one positive, poor and low significant correlation found related to "Fatalism" $(r=0,10, p=0,05)$, revealing that the longer the time elapses from the disease diagnosis the higher is the adoption of this coping responses.

Regarding the patients' undergoing type of treatment, there was a significant difference found between mean scores of the groups in the subscale "Fatalism" $(\mathrm{F}(3,342)=3.82, \mathrm{p}=0.01)$. The post-hoc Scheffé test settled the differences between patients who did not "undergo any treatment" $(M=12.14)$ and those who were submitted to "surgical and non-surgical treatment" (M=15,64), these latter having mostly adopted the "Fatalism".

Concerning the type of assistance provided to patients, outpatient $(n=202)$ and inpatient $(n=144)$, highly significant differences were found between the two groups related to "Anxious Preoccupation"
( $\mathrm{t}(344)=-4.03, \mathrm{p}=0.0001)$; low significant differences for "Fatalism" ( $\mathrm{t}(344)=2,28, \mathrm{p}=0,02)$ and for "Helplessness/Hopelessness" ( $\mathrm{t}(344)$ $=-2,08, p=0,03$ ). For these coping strategies, inpatients, compared to outpatients, revealed higher mean scores in "Anxious Preoccupation" and "Helplessness/Hopelessness", and a mean lower score for "Fatalism".

To analyse the coping strategies predictability index on the perception of spiritual well-being and quality of life of oncological patients in the final stage of the disease, a multiple linear regression analysis, using an eight step stepwise method was performed. For each regression models, the overall quality of life and spiritual well-being variables inclusion criteria were considered, using the FACT-G and FACIT-Sp scales and respective subscales. As predictor variables, the five coping strategies of the Mini-MAC scale. The standard coefficient values $(\beta)$ and their significance were considered, when comparing the relative effect of each predictive variable over the dependent variable [18]. Results in Table 4 show that in relation to the predictive value of coping strategies on the overall quality of life (FACT-G), 50\% of total variance was explained by variables "Helplessness/Hopelessness", "Fatalism", "Anxious Preoccupation" and "Fighting Spirit". The "Fatalism" and "Fighting Spirit" predicted an overall better quality of life.

Regarding the predictive value of the coping strategies on the overall spiritual well-being (FACIT-Sp), responses related to "Fatalism", "Helplessness/Hopelessness", "Fighting Spirit" and "Anxious Preoccupation" explained 56\% of total variance. Only "Fatalism" and "Fighting Spirit", which presented a positive predictive value, were able to predict a better overall spiritual well-being.

Thus, the results showed that the majority of the coping strategies, except for the "Cognitive Avoidance" revealed a high predictive value on the perception of quality of life and spiritual well-being of end-oflife patients. 
Table 4. Multiple linear regression between FACIT-Sp scales and subscales, of FACT-G and coping strategies.

\begin{tabular}{|c|c|c|c|c|}
\hline Criteria Variables & Adjusted R ${ }^{2}$ & $F(d f) p$ & Predictive Variables & $\beta(\mathbf{p})$ \\
\hline $\begin{array}{l}\text { FACT-G } \\
\text { Total }\end{array}$ & 0,50 & $69,73(5,338)^{* * * *}$ & $\begin{array}{l}\text { Helplessness/Hopelessness } \\
\text { Anxious Preoccupation } \\
\text { Fighting Spirit } \\
\text { Cognitive Avoidance } \\
\text { Fatalism }\end{array}$ & $\begin{array}{l}-0,27 * * * * \\
-0,24 * * * \\
0,20^{* *} \\
-0,02^{\mathrm{Ns}} \\
0,21^{* * * *}\end{array}$ \\
\hline $\begin{array}{l}\text { Physical well-being } \\
\text { subscale }\end{array}$ & 0,18 & $16,66(5,340)^{* * * *}$ & $\begin{array}{l}\text { Helplessness/Hopelessness } \\
\text { Anxious Preoccupation } \\
\text { Fighting Spirit } \\
\text { Cognitive Avoidance } \\
\text { Fatalism }\end{array}$ & $\begin{array}{l}-0,28^{* * *} \\
-0,14^{* *} \\
0,05^{\mathrm{Ns}} \\
-0,03^{\mathrm{Ns}} \\
0,05^{\mathrm{Ns}}\end{array}$ \\
\hline $\begin{array}{l}\text { Social/family well-being } \\
\text { subscale }\end{array}$ & 0,13 & $11,29(5,340)^{* * * *}$ & $\begin{array}{l}\text { Helplessness/Hopelessness } \\
\text { Anxious Preoccupation } \\
\text { Fighting Spirit } \\
\text { Cognitive Avoidance } \\
\text { Fatalism }\end{array}$ & $\begin{array}{l}0,05^{\mathrm{Ns}} \\
-0,09^{\mathrm{Ns}} \\
0,17^{*} \\
-0,03^{\mathrm{ns}} \\
0,26^{* * * *}\end{array}$ \\
\hline $\begin{array}{l}\text { Emotional well-being } \\
\text { subscale }\end{array}$ & 0,57 & $92,80(5,339)^{* * * *}$ & $\begin{array}{l}\text { Helplessness/Hopelessness } \\
\text { Anxious Preoccupation } \\
\text { Fighting Spirit } \\
\text { Cognitive Avoidance } \\
\text { Fatalism }\end{array}$ & $\begin{array}{l}-0,42 * * * * \\
-0,32 * * * * \\
0,10^{*} \\
-0,01 \\
0,10 * *\end{array}$ \\
\hline $\begin{array}{l}\text { Functional well-being } \\
\text { Subscale }\end{array}$ & 0,41 & $49,47(5,339)^{* * * *}$ & $\begin{array}{l}\text { Helplessness/Hopelessness } \\
\text { Anxious Preoccupation } \\
\text { Fighting Spirit } \\
\text { Cognitive Avoidance } \\
\text { Fatalism }\end{array}$ & $\begin{array}{l}-0,17 * * \\
-0,19^{* * * *} \\
0,25^{* * * *} \\
0,01^{\mathrm{Ns}} \\
0,23^{* * * *}\end{array}$ \\
\hline Criteria Variables & Adjusted $\mathbf{R}^{2}$ & $F(d f) p$ & Predictive Variables & $\beta(p)$ \\
\hline $\begin{array}{l}\text { FACIT-Sp } \\
\text { Total }\end{array}$ & 0,56 & $89,68(5,339)^{* * * *}$ & $\begin{array}{l}\text { Helplessness/Hopelessness } \\
\text { Anxious Preoccupation } \\
\text { Fighting Spirit } \\
\text { Cognitive Avoidance } \\
\text { Fatalism }\end{array}$ & $\begin{array}{l}-0,22 * * * * \\
-0,12 * * * \\
0,15^{* * *} \\
0,36^{\mathrm{Ns}} \\
0,43^{* * * *}\end{array}$ \\
\hline $\begin{array}{l}\text { Meaning/peace } \\
\text { subscale }\end{array}$ & 0,52 & $75,39(5,339)^{* * * *}$ & $\begin{array}{l}\text { Helplessness/Hopelessness } \\
\text { Anxious Preoccupation } \\
\text { Fighting Spirit } \\
\text { Cognitive Avoidance } \\
\text { Fatalism }\end{array}$ & $\begin{array}{l}-0,23^{* * * * *} \\
-0,13^{* * *} \\
0,19^{* * *} \\
0,02^{\mathrm{Ns}} \\
0,36^{* * * *}\end{array}$ \\
\hline $\begin{array}{l}\text { Faith } \\
\text { subscale }\end{array}$ & 0,36 & $40,96(5,340)^{* * * *}$ & $\begin{array}{l}\text { Helplessness/Hopelessness } \\
\text { Anxious Preoccupation } \\
\text { Fighting Spirit } \\
\text { Cognitive Avoidance } \\
\text { Fatalism }\end{array}$ & $\begin{array}{l}-0,16^{* *} \\
-0,07^{\mathrm{Ns}} \\
0,07^{\mathrm{Ns}} \\
0,03^{\mathrm{Ns}} \\
0,42^{* * * *}\end{array}$ \\
\hline
\end{tabular}

\section{Discussion}

The participants in this study adopted different types of coping strategies during this stage of the disease. Contrary to the study findings of Greer and Watson [9], the adoption of coping focused mainly on emotions, as the "Cognitive Avoidance" and "Fatalism", was somewhat expected, since this was the researchers' perception while interacting with patients throughout the entire research. These findings reveal that many patients when faced with the possibility of death, adopted the "Cognitive Avoidance" intentionally avoiding all thoughts on the disease, replacing them by positive emotional attention focus. However, other patients, were more likely to adopt coping strategies such as "Fatalism" and rely on God and health professionals, and trying to live the best life possible. The adoption of coping strategies such as "Cognitive Avoidance" and "Fatalism" may reveal patients' resignation and acceptance of the end-of-life. These data corroborate several authors' findings $[6,19,20-22]$ suggesting that people, when faced with perceived irreversible situations, tend to adopt avoidance as a way to control stress and the psychological impact. The remaining and less adopted assessed coping responses were related to "Fighting Spirit", the "Anxious Preoccupation" and "Helplessness/Hopelessness".

Some patients under specific circumstances, have adopted a more confrontational coping skills, related to the "Fighting Spirit". These patients, although aware of their health condition, believed they could have some control over the situation, and their disease was perceived as a challenge to be met. On the other hand, when faced with the worsening of the disease, they adopted a response as "Anxious Preoccupation", expressing rage and anger feelings towards the disease. Other patients adopted different coping skills related to "Helplessness/ Hopelessness" expressing a total disbelief, and complete loss of control attitude towards their situation.

This study results indicate that the type of coping responses adopted by end-of-life patients with oncological diseases, varied according to gender, age, education and religion. Findings reveal that men often adopted coping responses related to "Fighting Spirit" whilst women used "Helplessness/Hopelessness" which corroborate some authors outcomes $[23,24]$. This difference might be explained by a combination of social and biological characteristics and hormonal related factors, but also by the gender role in modern societies, determining each gender sociably acceptable feelings and behaviours [25]. Aging and the perception on the impending death, influenced patients to adopt less confrontational coping focusing on "Anxious Preoccupation" and "Fighting Spirit", shifting to a resignation attitude. This idea 
corroborates Ryan's findings, that aging eases acceptance of the disease condition and end-of-life [26].

These study findings also evidence that higher educational levels meant a more frequent adoption the "Fighting Spirit". This result corroborates Carver et al. [19] meaning that people with higher educational levels are more likely to choose more adaptive and active coping responses. An improved educational level might have enabled patients a better understanding over their situation and help them perceive that this knowledge would be a valuable contribution to the disease control.

This study results also show that religion has influenced the adoption of coping skills. Believers, those professing a religion or belief were found to adopt mainly coping related to "Fatalism", relying totally on God, or "Cognitive Avoidance" revealing resignation and abstraction of the situation. This is a rather surprising but understandable result. It is expected that "believers" have a more determined attitude, but spiritual orientation is also capable of influencing the type of response, in a way that it provides a philosophy of life with related support, purpose and meaning that will influence the patient in crisis situations [27,28].

Regarding the potential influence of the clinical variables in the coping skills it was found that the longer time elapsed from diagnosis, the greater the use of "Fatalism". This finding could indicate that the patient was progressively more aware of the irreversibility of the disease and the impending death. This awareness has caused changes in patients' personal values, aiming to a better quality of life, to spend more time with significant others and also to accomplish some personal goals.

In the course of the disease, patients who were undergoing "surgical and nonsurgical treatments" were more likely to adopt "Fatalism", compared to those patients who had not been submitted to any treatments. This result might indicate that for those patients undergoing treatment, the perception that everything had been done, influenced them to gradually accept their condition.

The type of assistance provided to patients at the time of data collection (inpatient or outpatient) was also found to influence the adopted coping skills. In this context, outpatients were more likely to adopt "Fatalism" rather than "Anxious Preoccupation". On the other hand, inpatients often adopted the "Anxious Preoccupation" and "Helplessness/Hopelessness", as a result of their awareness on the worsening of the condition.

Results have showed that the adoption of "Helplessness/ Hopelessness" and "Anxious Preoccupation" predicted a poorer overall quality of life and for each specific dimensions, as evidenced in the study of Anagnostopoulos et al. [29]. These were proved to be more problematic adaptive coping skills, since they could potentially trigger negative emotions such as hopelessness, helplessness, anxiety and anger. On the other hand "Fighting Spirit" and "Fatalism" proved to be predictive of a better perception of quality of life. Since the "Fighting Spirit" is characterized by a confrontational attitude towards the disease and "Fatalism" as a resigned acceptance, this reality may be considered contradictory. These findings may be explained by the adoption of these coping responses by different patients, according to their personal characteristics, or by the same patient, throughout the course of the disease and self-assessment over the health condition.

The adoption of "Helplessness/Hopelessness" and "Anxious Preoccupation" predicted a worsening symptoms' perception and consequently the feeling of getting sicker, as well as greater frustration in relationships, especially with friends and family. Patients tended to perceive greater inability to perform daily activities and to accept the disease, and experienced dissatisfaction with their quality of life. At the emotional level, predictive factors related to sadness, unhappiness and the inability to cope with the disease and increasing concerns about health and death were also found.

When analysing the predictive role of coping skills on the spiritual well-being, it was also found that only "Fatalism" and "Fighting Spirit", predicted a better perception of patients' well-being. The adoption of these two types of coping strategies strengthened the dimension "Meaning/Peace", in a way it favoured the search for direction and meaning to their suffering and their lives. On the other hand, the adoption of "Helplessness/Hopelessness" and "Anxious Preoccupation" had a negative impact on self-balance and peace of mind. Concerning the "Faith" dimension, only "Fatalism" revealed to have a significant positive predictive role on patients, enhancing indepth religious and spiritual experiences. These experiences helped patients to find the necessary spiritual strength to experience end-oflife and find inner peace.

This study outcomes show the relevance of an approach to oncological end-of-life patients focused on physical symptoms control, but, most importantly, they also highlight the significance of different assessments. When dealing with the disease, the coping skills adopted by patients may affect quality of life in the various dimensions and spiritual well-being and increase suffering. Hence, coping should be considered a major attention focus to health professionals, namely nursing, supporting patients in the adoption of more adaptive coping skills, potentially promoting better quality of life and spiritual wellbeing.

\section{References}

1. Manzanera RS (2004) Cuidadospaliativos: avances sin final. Alcalá la Real: editorial Formação Alcalá S.L.

2. Kubler-Ross E (1975) Sobre la morte y los moribundos. Barcelona: Grijalbo.

3. Benkel IMS, Wijk HRN and Molander UMD. Using coping strategies is not denial: Helping loved ones adjust to living with a patient with a palliative diagnosis. Journal of Palliative Medicine 2010. 13: 119-123.

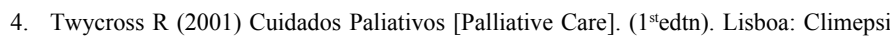
Editores.

5. Lazarus RS, Folkman S (1986) Estrés e procesoscognitivos. Madrid: Martinez Roca.

6. Carver CS, Scheier MF (1994) Situational coping and coping dispositions in a stressful transaction. J Pers Soc Psychol 66: 184-195.[Crossref]

7. Lazarus RS, Folkman S (1984) Stress, appraisal, and coping. Springer: New York.

8. Antoniazzi AS, Dell'Aglio DD, Bandeira DR (1998) The concept of coping: A theoretical review. Estudos de Psicologia 3: 273-294.

9. Greer S, Watson M (1987) Mental adjustment to cancer: its measurement and prognostic importance. Cancer Surv 6: 439-453.[Crossref]

10. Watson M, Law M, Santos M (1994) The Mini-MAC: Furter development of mental adjustment to cancer scale. Journal of Psychosocial Oncology 12: 33-46.

11. Pais-Ribeiro JL, Ramos D, Samico S (2003) Contribution to a conservative validation of a Portuguese version of the Mini Mental Adjustment to Cancer Scale (Mini-MAC)]. Psicologia, Saúde \& Doenças 4: 231-247.

12. Folstein MF, Folstein SE, McHugh PR (1975) "Mini-mental state". A practical method for grading the cognitive state of patients for the clinician. J Psychiatr Res 12: 189-198. [Crossref]

13. Pereira FM, Santos CS (2014) Initial validation of the Mini-Mental Adjustment to Cancer (Mini-MAC) scale: study of Portuguese end-of-life cancer patients. Eur J Oncol Nurs 18: 534-539.[Crossref]

14. Cella DF, Tulsky DS, Gray SB (1993) The Functional Assessment of Cancer Therapy 
Scale: development and Validation of general measure. Journal of Clinical Oncology 11: $570-579$.

15. Pereira FMP, Santos CSVB (2011a)Estudo de adaptação cultural e validação [Study of cultural adaptation and validation] of the Functional Assessment of Cancer TherapyGeneral in palliative care. Referênca 5: 45-54.

16. Peterman AH, Fitchett G, Brady MJ, Hernandez L (2002) Measuring spiritual Wellbeing in people with cancer: the functional assessment of chronic illness therapySpiritual Well-being Scale (FACIT-Sp), Annals of Behavioral Medicine 24: 49-58.

17. Pereira FMP, Santos CSVB (2011b)Estudo de adaptação cultural e validação [Study of cultural adaptation and validation] of the Functional Assessment Chronic IIIness Therapy-Spiritual Well-Being (FACIT-Sp). Cadernos da Saúde 4: 37-45.

18. Pestana MH and Gageiro JN (2005)Análise de dados para as Ciências Sociais: A complementaridade do SPSS [Data analysis for Social Sciences: SPSS complementarity]

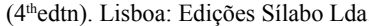

19. Carver CS, Scheier F, Weintraub JK (1989) Assessing coping strategies: A theoretically based approach. Journal of Personality and Social Psychology 56: 267-283.

20. Carver CS (1997) You want to measure coping but your protocol's too long: consider the brief COPE. Int J Behav Med 4: 92-100.[Crossref]

21. Lazarus RS (2000) Evolution of a model of stress, coping and discrete emotions. In V.H. Rice (Ed.). Handbook of stress, coping and health: Implications for nursing research, theory and pratice. (Cap 9, pp.195-222). Sage Publications:London.
22. Bradley SE, Frizelle D, Johnson M (2010) Coping with terminal illness: the experience of attending Specialist Palliative Day Care. J Palliat Med 13: 1211-1218.[Crossref]

23. Daly P, Juban RL (1999) Cognitive Processes, strain and stress: Gender differences in stress propensity indicators. Anxiety, stress and coping Journal 12: 41-63.

24. HagedoornM, Buunk BP, Kuijer RG, Wobbes (2000) Couples dealing with cancer, role and gender differences regarding psychological distress and quality of life. Psychooncology 9: 232-242.

25. Bird CE, Rieker PP (1999) Gender matters: an integrated model for understanding men's and women's health. Soc Sci Med 48: 745-755.[Crossref]

26. Ryan PY (2005) Approaching death: a phenomenologic study of five older adults with advanced cancer. Oncol Nurs Forum 32: 1101-1108.[Crossref]

27. Hill PC, Pargament KI (2003) Advances in the conceptualization and measurement of religion and spirituality. Implications for physical and mental health research. $\mathrm{Am}$ Psychol58: 64-74.[Crossref]

28. Jenkins RA and Pargament KI (1995) Religion and spirituality as resources for coping with cancer. Journal of Psychosococial Oncology 13:51-74.

29. Anagnostopoulos F, Kolokotroni P, Spanea E (2006) The Mini-Mental Adjustment to Cancer (Mini-MAC) scale: Construct validation with a Greek sample of breast cancer patients. Psychooncology 15: 79-89.

Copyright: $\left({ }^{2} 2016\right.$ Pereira FMP. This is an open-access article distributed under the terms of the Creative Commons Attribution License, which permits unrestricted use, distribution, and reproduction in any medium, provided the original author and source are credited. 